\title{
AC 2008-1245: DISTANCE LEARNING WITH LIMITED BANDWIDTH
}

\section{Henry Chaya, Manhattan College}

Brother Henry Chaya is an Associate Professor of Electrical and Computer Engineering at Manhattan College in New York City. He is currently on leave to serve as chairperson of the Computer Information Systems department at Bethlehem University in the West Bank. Both institutions are sponsored by the Brothers of the Christian Schools of which the author is a member. 


\title{
Distance Learning with Limited Bandwidth
}

\begin{abstract}
Access to quality technical education for Arabs living in the West Bank is essential for improving the economy of the region. Instructors living in the area have limited exposure to the latest technology for political and economic reasons. To address this problem, the author decided to offer a course in his area of expertise to Arab students from his home institution in the USA using distance learning.

A course in computer architecture was offered to junior-level students at an Arab university. It is a required course in their Information Systems curriculum. There were many challenges to overcome. One of them was that available internet bandwidth was extremely limited. For this reason the course was conducted asynchronously.

The paper will discuss how we dealt with the technical limitations and how we assessed the effectiveness of the course. Finally the author will discuss his experiences working with Arab students in this mode of learning.

\section{Introduction}

During the 2003-2004, the author was granted leave to visit an Arab university in the West Bank. During his stay there he helped to establish a new major in Computers and Information Systems. One of the required courses in the curriculum was titled "Computer Architecture". However there was no one on the staff with the expertise to teach a course in modern computer hardware. So it was decided that when the author returned to the USA, he would offer this course through distance learning. An on-site faculty member would assist with course logistics. To date, the course has been offered twice in this manner.
\end{abstract}

\section{Course Content}

The course uses the text Computer Organization and Design by Patterson and Hennessy, third edition published by Morgan Kaufman. The major topics are Turing machines, data representation, computer arithmetic, instruction set architecture, procedure calls in MIPs, compiler optimization, MIPs single-cycle machine, pipelining, memory systems, peripheral interfacing and RAID. We rely on the MipsIt ${ }^{1}$ development environment for programming assignments using the MIPS architecture.

\section{Challenges}

Some of the challenges we faced were limited Internet bandwidth, restricted availability of computers, constrained finances and language differences. The biggest technical challenge was the limited bandwidth.

At the time this course was offered, the Arab university had a single $1 \mathrm{Mbit} / \mathrm{sec}$ Internet connection for the entire campus at a cost of $\$ 1200$ per month. During the hours students are on campus, all downloads of audio or video content had to be blocked. This restriction made any sort of synchronous interaction with students impractical except for text messaging or chat. It was not feasible to upload any files from the USA that were larger than a few megabytes

Some students did not have personal computers at home, and had to rely on university computer labs which were open from 8 AM to 4 PM Monday to Friday. 
The official language of instruction at the Arab university is English. The majority of the students are fluent in English, but a significant number have difficulties with it. In practice, many instructors use a mixture of English and Arabic in their lectures. Regrettably the author has little facility with Arabic so some students must rely on other students and teachers for explanations.

\section{Methodology of Instruction}

All lectures were prerecorded using the software Camtasia Studio by TechSmith to produce Windows Media videos. All of the recordings were screen casts capturing only audio and the PC's video display. No video image of the speaker was used in order to conserve memory. Most of the videos were PowerPoint presentations recorded on a tablet PC. Cursor movements and pen strokes are captured to direct student attention during the lecture. The size of the video files was about $1 \mathrm{MB}$ per minute.

Each week the author prepared about three hours of videos. He organized the video files, the PowerPoint slides and other supporting documents into a single folder with a simple html file serving as the "table of contents". These were placed in a single compressed file on the author's personal website. A technician from the Arab university would then download the file in the off hours and install it on a local server. As stated before, it was impractical to upload such a large file from the USA.

The Arab university uses Moodle software for its electronic course management system. It was possible for the author to use this tool for posting grades, assignments and other small documents. It could also be used to collect most of the assignments. Students also used email to submit assignments and questions to the instructor.

A faculty member at the Arab university was assigned a one-credit load to act as on-site coordinator. He met with the class once a week. At this meeting, students could discuss any issues related to the course. The author in New York kept in close contact with the on-site coordinator to make announcements, offer encouragement and monitor student progress.

Since the class size was over thirty five students, it not feasible to give tests electronically. The local coordinator proctored conventional paper exams. The answer sheets were scanned and emailed to the author for grading.

Each semester the author flew to the West Bank to give several lectures in person. The purpose was to allow the students to make personal contact with the author and vice versa. This was well worth the time and expense.

\section{Course Assessment}

The course first ran in spring 2006 with thirty six students. The course was successful enough that we decided to try it again in spring 2007 with thirty seven students. In order to get some quantitative assessment of the course, the author administered a brief survey to the spring 2007 class. Thirty one out of the thirty seven students responded. The survey is reproduced below with quantitative results for itemized questions. 
1 How many of the course videos can you view during the week?
13 All of them
- 7 About half of them
_ None of them
11 Some of them
_ A few of them

2 Where do you listen to the videos? (Check all that apply)

_ 8_In a University lab _ 28_ At home _ _ _ On a friend's computer

Another place (please specify)

3 How well are you able to understand the material in the videos? (Check one)

_1_ I understand all the material very well.

16_ I understand most of the material

_. I understand enough of the material adequately.

_5_ I understand about half the material.

I understand only some of the material

_ I understand very little of the material.

4 What can be done to improve the quality of the videos?

5 When you have a question about course material, how do you get it answered besides asking a friend?

_18_ I send Br Henry an email

_6_ I ask the on-site coordinator

_._ I ask another teacher

6_ I do not like to ask teachers questions

6 Are you satisfied with the way this course is offered online?
_ 8 _ Very satisfied
3 _ Its just ok.
_1_ I don't like it at all
$\underline{14}$ Satisfied
5 There are problems

7 What do you like most about the course?

8 What do you like least about the course?

In question 4 about video quality, twelve students mentioned they were too long and eight students wanted more worked out examples. One student indicated he could not fast forward or reverse the video.

For question 7, six students liked the novelty of distance learning. Seven students liked the ability to replay videos for review. Five students mentioned the flexibility of time and place for viewing lectures. Five students liked the subject matter. Four students mentioned teaching style. Three mentioned the simulation software and two liked the fact that they had to be self reliant.

For question 8 , seven students mentioned the length of the videos. Two mentioned the absence of a teacher. Three mentioned the delay in having questions answered by email. Three thought the subject matter was too complex. Two had a problem with the language. Three thought there were too many assignments. Two mentioned that others were copying assignments. 


\section{Observations}

The student comments about the length of the videos are justified. As the author got used to making videos, he tended to have longer lectures. Some ran to about an hour and fifteen minutes. After getting the survey results, the author limited the videos to 50 minutes.

Another comment from the survey was about the inability to fast forward or reverse the videos. This was sometimes the case when streaming the video from a distant server, but it was possible to fast forward and reverse when videos were downloaded to a local computer or server.

In the survey students commented that they could replay particular sections of the video to clarify points they might have missed in the first hearing. Many students were not fluent in English and often do not understand certain points made in an oral lecture. The recorded videos help to alleviate this problem.

During the first course offering in spring 2007, all the students passed with the majority of the grades being B or B+. During the second offering in spring 2007, again all students passed. The majority of grades were $\mathrm{A}$ and the class average of $87 \%$.

In the fall of 2007 the author had the opportunity to teach 18 of the same students from the spring 2007 class in a conventional lecture course. The course title was "Artificial Intelligence". This time there were only $4 \mathrm{~A}$ 's and the class average was 80 . When students were questioned about this they offered two reasons. First, the material in Artificial Intelligence was more difficult than Computer Architecture. Second, since students had less contact with the instructor during the on-line course, they were less certain about what he expected so they studied more diligently. This later observation is consistent with comments made in the survey that students had to be more self-reliant in the learning process. This might lead one to conclude that when students are given more responsibility for their own learning, they perform better.

\section{Conclusion}

In the opinion of this author, these attempts to offer a distance learning course to undergraduates were a success. The motivation of the students is the most important reason for this. This project has demonstrated that it is quite feasible to give undergraduate students the benefit of expert teaching skills that are otherwise unavailable to them. Indeed the author feels privileged to have had this opportunity.

$1 \mathrm{M}$. Brorsson. MipsIt-a simulation and development environment using animation for computer architecture education. In Proceedings of 2002 Workshop on Computer Architecture Education, pages 65-72, May 2002. Anchorage, Alaska. 